APDA - NTS - 3

\title{
DETERMINATION OF THE SAFETY ROD DROP TIME IN THE ENRICO FERMI REACTOR
}

\author{
By \\ R. E. Horne \\ A. E. Klickman
}




\section{DISCLAIMER}

This report was prepared as an account of work sponsored by an agency of the United States Government. Neither the United States Government nor any agency Thereof, nor any of their employees, makes any warranty, express or implied, or assumes any legal liability or responsibility for the accuracy, completeness, or usefulness of any information, apparatus, product, or process disclosed, or represents that its use would not infringe privately owned rights. Reference herein to any specific commercial product, process, or service by trade name, trademark, manufacturer, or otherwise does not necessarily constitute or imply its endorsement, recommendation, or favoring by the United States Government or any agency thereof. The views and opinions of authors expressed herein do not necessarily state or reflect those of the United States Government or any agency thereof. 


\section{DISCLAIMER}

Portions of this document may be illegible in electronic image products. Images are produced from the best available original document. 


\section{FOREWORD}

This report is one of a series of reports on the low-power (up to 1 $\mathrm{Mwt}$ ) and high-power (up to $200 \mathrm{Mwt}$ ) nuclear testing of the Enrico Fermi reactor. The Nuclear Test Program is planned, directed, and evaluated by Atomic Power Development Associates, Inc. (APDA). The tests are conducted by Power Reactor Development Company (PRDC). The reactor proper is owned and operated by PRDC. The steam generators and electrical generation facilities are owned by The Detroit Edison Company (DECo).

Many people have contributed to the success of the nuclear testing of the Fermi reactor. Listed below are the names of those people, exclusive of the authors, who made a significant contribution to some phase of the work reported in this document.

APDA

C. E. Branyan

J. Levine

H. A. Wilber

M. Ziniak

\section{PRDC}

E. L. Alexanderson

D. A. Erdman

P. M. Harrigan 
TABLE OF CONTENTS

$\underline{\text { Page }}$

LIST OF ILLUSTRATIONS ................ 4

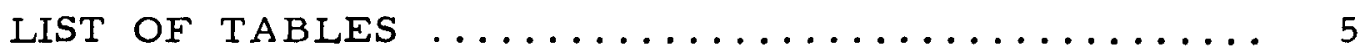

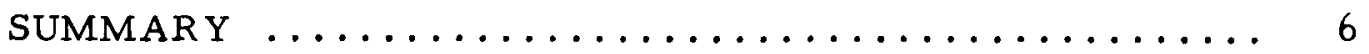

I PURPOSE OF TEST $\ldots \ldots \ldots \ldots \ldots \ldots \ldots \ldots \ldots \ldots$

II DESCRIPTION OF THE ENRICO FERMI REACTOR $\ldots . .8$

A. GENERAL DESCRIPTION ................ 8

B. DESCRIPTION OF THE SAFETY RODS ......... 13

C. DESCRIPTION OF THE SAFETY

ROD DRIVE MECHANISM .............. 15

III $\quad$ EXPERIMENTAL PROCEDURE $\ldots \ldots \ldots \ldots \ldots \ldots \ldots \ldots \ldots$

A. DESCRIPTION OF THE TEST ............. 19

B. EXPERIMENTAL EQUIPMENT .............. 21

1. Ion Chamber ..................... 21

2. Fission Counter and $\mathrm{BF}_{3}$ Proportional Counter ... 21

3. Keithley Micro-Microammeter ............ 24

4. Sanborn Recorder ................... 24

C. REACTOR PLANT CONDITIONS ............ 24

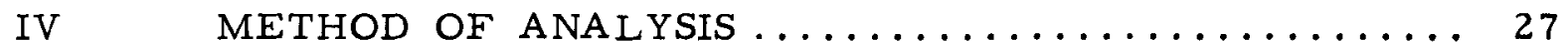

A. ANALYSIS OF THE ROD DROP DATA ......... 27

1. Time Dependent Reactivity and Flux Relationship . 27

2. Data Reduction and Analysis ............ 28

3. Basic Data ....................... 30

B. DETERMINATION OF ROD WORTH ........... 31

C. DETERMINATION OF ROD DROP TIME ....... 31

V EXPERIMENTAL RESULTS ................ 33

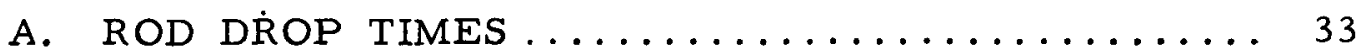

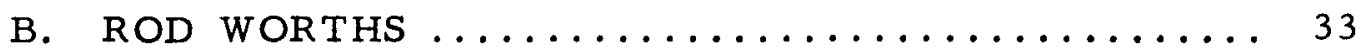

VI $\quad$ CONCLUSIONS $\ldots \ldots \ldots \ldots \ldots \ldots \ldots \ldots \ldots \ldots \ldots \ldots \ldots \ldots$

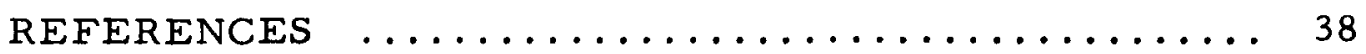

ACKNOW LEDGEMENT $\quad \ldots \ldots \ldots \ldots \ldots \ldots \ldots \ldots \ldots \ldots . \ldots \ldots$ 


\section{LIST OF ILLUSTRATIONS}

$\underline{\text { Figure }}$

Title

$\underline{\text { Page }}$

1

Perspective View of Reactor................. 9

2

Reactor Cross Section ................... 10

3

Location of Neutron-Counter Tubes in Graphite Shield ... 12

Safety Rod Assembly .................... 14

5

Safety Rod Drive Assembly ................ 16

6

Safety Rod Drive Extension $\ldots \ldots \ldots \ldots \ldots \ldots \ldots$

7

Safety Rod Arrangement and Core Loading During Test ... 20

8

Arrangement of Experimental Equipment ......... 22

9 Neutron Counter Tubes Nos. 3 and 4, Showing the Location of the Detectors ................. 23

Typical Sanborn Trace of a Rod Drop Experiment .......

11 Typical Flux Decay and Calculated Reactivity for

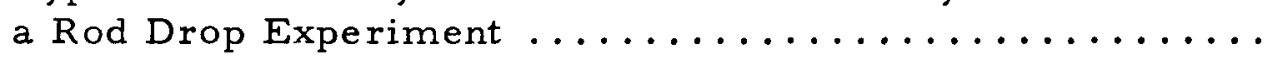




\section{LIST OF TABLES}

Table

I

II

III

IV

V
Title

$\underline{\text { Page }}$

Delayed Neutron Data.

Experimental Values of the Safety Rod

Drop Time Intervals

Predicted Values of the Safety Rod

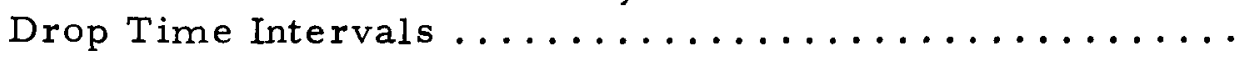

Experimental and Predicted Safety Rod Worths

Boron Loading of the Safety Rods

36 
The safety rod drop tests for the Enrico Fermi reactor were conducted on October 4 and 5, and November 11, 1963. The experimental method was based on an analysis of the flux decay in the reactor after the rod or rods had been dropped. From the data, three sets of results were determined: (1) the time required for the seven safety rods, singly and in specified groups, to be inserted into the reactor, (2) the effect of reactor temperature and coolant flow rate on the rod drop time and (3) the reactivity worths of the rods.

During the time a rod was dropped, a high-speed recording oscillograph was used to record the neutron responses of an in-core fission counter, and an ion chamber and $\mathrm{BF}_{3}$ detector both of which were located outside the reactor in the graphite shield. In addition to recording the flux decay during the drop, the voltages across the latch-open microswitch and the latch magnet were recorded prior to and during the drop so that the exact time of rod release could be determined.

Analysis of the results indicated that all measured drop times agreed closely with the predicted values. The time required to insert a safety rod after a manual scram ranged from 588 to $658 \mathrm{msec}$; the predicted time was $720 \mathrm{msec}$. Furthermore, no effect on the safety rod drop time was observed when the reactor coolant flow and temperature were varied.

The measured worths of the individual safety rods ranged from $\$ 1.16$ to $\$ 1.50$ and the reactivity effect of inserting all seven safety rods simultaneously was approximately $\$ 8.00$. The measured values average about 15 per cent less than predicted. 


\section{PURPOSE OF TEST}

The primary purpose of the safety rod drop tests conducted in the Enrico Fermi reactor was to determine, by means of nuclear kinetic measurements, the time required to insert the seven safety rods, both individually and ganged, into the reactor after the initiation of a manual scram. These measurements were required to confirm the design calculations of the rod insertion time. This data is important from a safety aspect because it can be used to estimate the time required to shutdown the reactor from full power should a scram become necessary. As part of the test, the sodium coolant flow rate and the reactor temperature were varied to determine whether these two parameters had any effect on the rod drop time. It was necessary to make nuclear measurements of the safety rod insertion times because it was not possible to make an accurate mechanical measurement of the scram time in the reactor due to the design of the safety rod extensions.

The secondary purpose of the tests was to determine the worth of the safety rods using the data obtained during the drop tests. The rod worths obtained in this test will be used as an independent check on the worths that are obtained in later tests by means of subcritical and critical calibrations. 


\section{DESCRIPTION OF THE ENRICO FERMI REACTOR}

\section{A. GENERAL DESCRIPTION}

The Enrico Fermi reactor and its associated structures are shown in perspectiye in Figure 1. The reactor is contained in a stainless steel reactor vessel sealed at the top by a rotating shield plug which supports the control mechanisms, the hold-down mechanism and the fuel handling mechanism. The reactor vessel is surrounded by borated and plain graphite neutron shielding material which is contained inside the primary shield tank. The reactor is of the fast-breeder type, cooled by sodium, and operated at essentially atmospheric pressure. The maximum reactor power with the first core loading (Core A) is $200 \mathrm{Mwt}$.

The core and blanket, located in the lower reactor vessel, consist of square subassemblies containing the fuel pins and blanket rods arranged to approximate a cylinder about 80 inches in diameter and 70 inches high. The core, contained in the central portion of the core subassemblies, approximates a right cylinder 31 inches in diameter and 31 inches high; it is axially and radially surrounded by breeder blankets. The fuel in Core A consists of zirconium-clad pins containing U-10 w/o molybdenum alloy with the uranium enriched to $25.6 \mathrm{w} / \mathrm{o} \mathrm{U}-235$. Each fuel subassembly in the core contains 140 fuel pins for a total mass of approximately 4.75 kilograms of U-235 per subassembly. The blanket is depleted U-3 w/o molybdenum alloy.

The reactor cross section, shown in Figure 2, indicates the placement of individual components within the lower reactor vessel. There is a total of 149 central lattice positions that are occupied by core and inner radial blanket subassemblies, the neutron source, and the 10 operating control and safety rod channels. All these positions are supplied with sodium coolant flowing upward from a high-pressure plenum which is connected to the discharge lines of the three primary sodium pumps. The coolant flows upward through the individual core and inner radial blanket subassemblies into a large upper plenum and from there by gravity to the three intermediate heat exchangers and then to the suction side of the primary pumps. Sodium also is used in the secondary cooling system.

The lattice positions surrounding the inner radial blanket comprise the outer blanket area, and when filled with outer radial blanket subassemblies they form an annular region whose top and bottom are at the same elevation as the top and bottom of the inner radial blanket. Surrounding the outer radial blanket are lattice positions used for stainless steel subassemblies. These subassemblies provide thermal and neutron shielding. The outer radial blanket and shielding lattice positions are supplied with sodium 


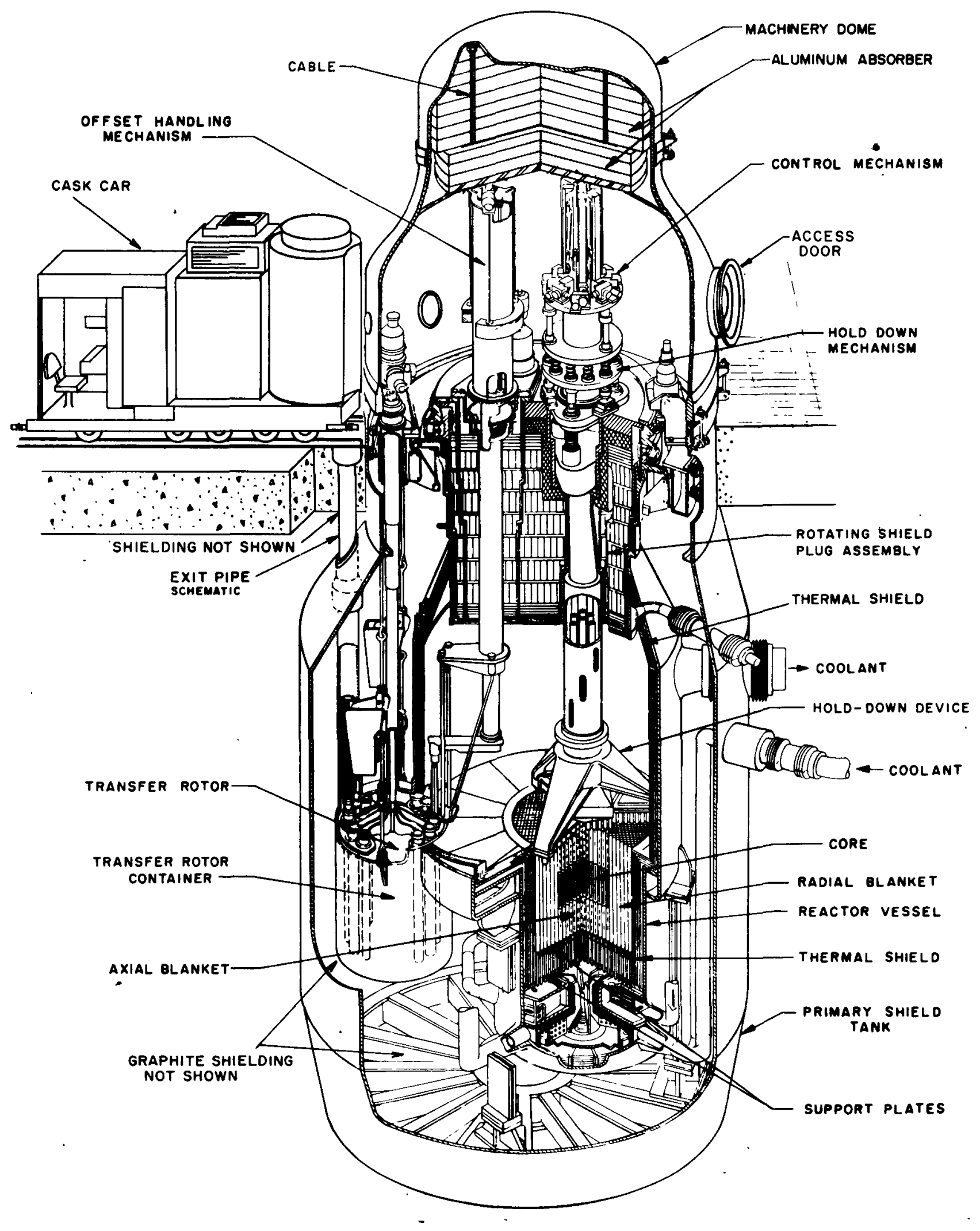

FIG. I-PERSPECTIVE VIEW OF REACTOR 
$$
\text { . }
$$ 
coolant from the low-pressure plenum. The sodium from the low-pressure plenum, after cooling the blanket and thermal shield subassemblies, is mixed in the upper plenum with the sodium from the core before flowing to the intermediate heat exchangers.

The reactor is controlled by two operating control rods and seven safety rods. Provisions have been included in the design for an eighth safety rod. The rods are of the poison-type, containing boron carbide $\left(\mathrm{B}_{4} \mathrm{C}\right)$ in which the.boron is enriched in boron-10 (B-10). One operating control rod is for regulating purposes and the other for shimming; the average reactivity insertion rates of these rods are approximately one cent per second and one cent per minute, respectively. Both rods have approximate reactivity worths of 46 cents. The seven safety rods, which are spaced around the center of the core, provide shutdown reactivity. During operation of the reactor, the safety rods are held just above the axial blanket section of the core so that they can be rapidly inserted into the core if a scram becomes necessary. Each of the safety rods has a reactivity worth in excess of $\$ 1.00$. The movements of the control and safety rods are actuated from the top. During fuel reloading, they are delatched from their drive extensions to allow them to remain in the core.

The neutron detectors (fission chambers and ion chambers) for normal reactor operation at power, are located in six neutron-counter tubes (NCT) embedded in the graphite neutron shield surrounding the reactor vessel (Figure 3). There are eleven channels of nuclear instrumentation distributed throughout the six neutron-counter tubes in a manner which will cover the full power range during reactor operation. These detectors located in these channels are designed to operate at temperatures up to $500 \mathrm{~F}$.

An antimony-beryllium ( $\mathrm{Sb}-\mathrm{Be}$ ) neutron source is located in the reactor at the core-blanket interface (Figure 2) to provide a neutron flux at the neutron detectors during reactor start-up and to maintain a flux when the reactor is shutdown. The radioactive antimony portion of the source is made as a separate piece for easy replacement and is in the form of a rod approximately 0.7 inch in diameter and 25 inches long. The radioantimony rod fits inside a beryllium assembly which is in the form of a hollow cylinder inside a stainless steel can having the external dimensions of a normal core subassembly fuel can. The handling head on the antimony section allows it to be inserted and withdrawn from the beryllium by means of the normal fuel handling mechanism. The beryllium portion must be installed and removed from the reactor through a special access port in the reactor vessel shield plug.

Additional information concerning the reactor design may be found in the Enrico Fermi Hazards Summary Report. 1 

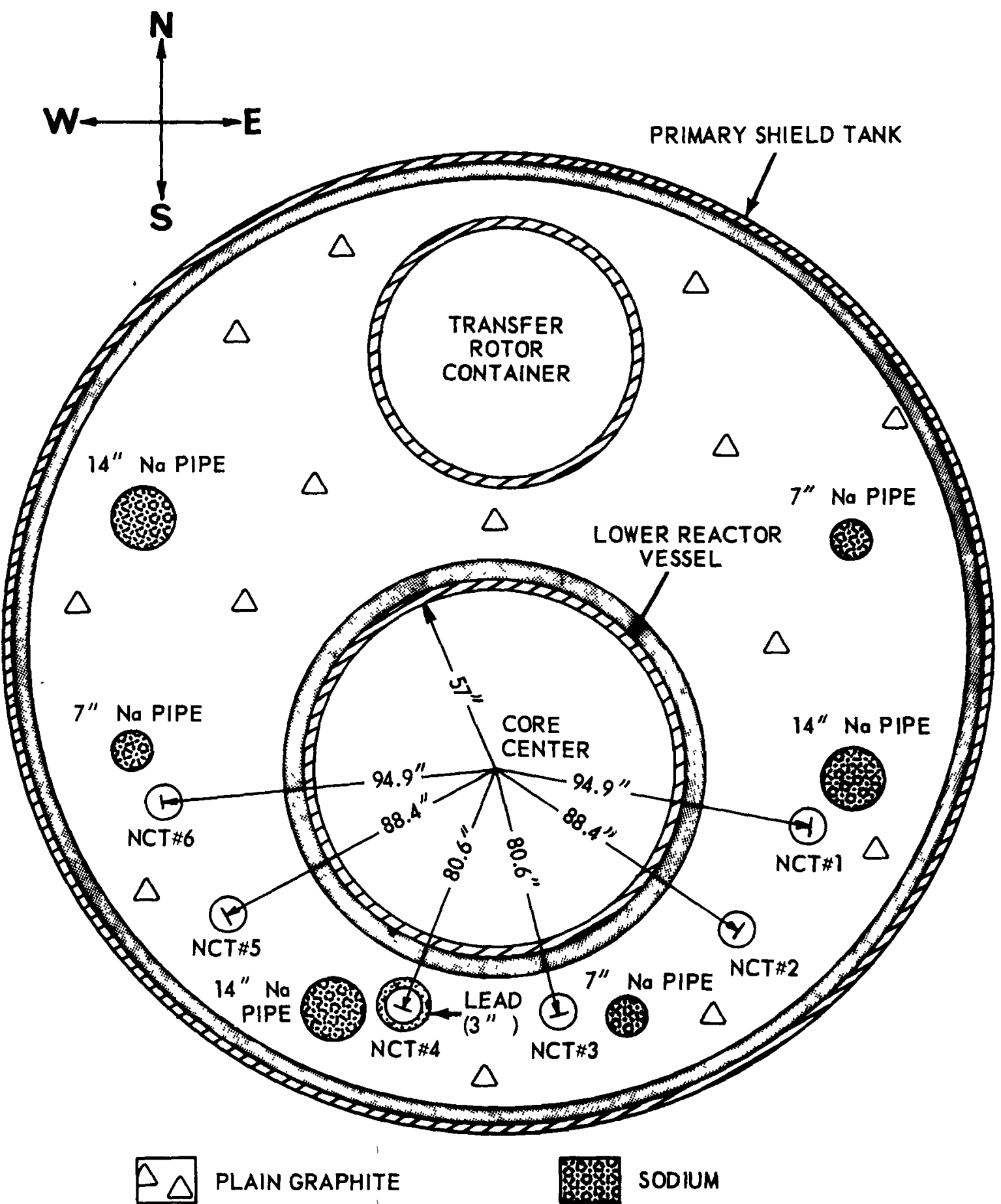

PLAIN GRAPHITE

SODIUM

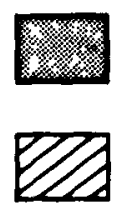

5\% BORATED GRAPHITE

(6" THICK)

Hign LEAD

STEEL

FIG. 3 LOCATION OF NEUTRON-COUNTER TUBES IN GRAPHITE SHIELD 


\section{B. DESCRIPTION OF THE SAFETY RODS}

The Enrico Fermi reactor has seven installed safety rods. Provision for an eighth rod has been included in the design and construction of the plant. Each of the seven safety rods are poison-type rods, identical in construction and operation. Each safety rod is made up of four sections (Figure 4). These sections are the dash ram, poison section, extension rod and handling head. The dash ram is the piston section of a hydraulic shock absorber which absorbs the kinetic energy of the rod after its free fall. The extension rod is a transition piece connecting the poison section to the pickup head, and the pick-up head is the portion of the rod which enables it to be handled within the reactor by the offset handling mechanism.

The dash ram is a double-tapered piston with an effective length of 6 inches. This piston fits firmly into the guide tube dash pot and during a scram acts as a hydraulic shock absorber to dissipate the kinetic energy of the free-falling safety rod. Nearly constant deceleration is obtained with this dash ram design, and the velocity of the rod is nearly zero as it reaches the bottom of the dash pot.

The poison section is approximately 36 inches long and consists of a 2-1/4-inch-diameter stainless steel tube, which contains six hermetically sealed, 5/8-inch-diameter stainless steel tubes. These tubes are filled with hollow cylinders of boron carbide $\left(B_{4} C\right)$, hot pressed to approximately theoretical density. A total of approximately 525 grams of B-10 are contained in each rod in the form of boron enriched with $57 \mathrm{w} / \mathrm{o}$ of the $\mathrm{B}-10$ isotope. The rod worth is more than $\$ 1.00$. Heat generated in the $\mathrm{B}_{4} \mathrm{C}$ is removed by sodium flow directed around the tubes. At the lower end of the rod, just above the dash ram, sixteen 3/8-inch-diameter holes admit sodium to the poison section of the tube from the guide tube. The sodium then circulates up a round the poison containment tubes and leaves the rod immediately below the handling head.

The extension rod is a transition piece which connects the poison section to the handling head. This section is enclosed by the upper shell and contains an Inconel-X spring which is compressed by the lower end of the safety rod drive extension when the rod is latched. The rod accelerating or cocking spring is compressed to about 110 pounds by the downward motion of the drive extension and upon scram imparts an average acceleration of about $2 \mathrm{~g}$ to the safety rod. The safety rod stroke is about 54 inches and it achieves a maximum velocity of $6.5 \mathrm{ft} / \mathrm{sec}$ during scram.

As shown in Figure 4, the neck of the handling head, located at the top of the rod, is enclosed by a collar having two parallel conical gripping shoulders about 1 inch apart. The upper shoulder, of smaller diameter than the lower shoulder, is gripped by the drive extension latch, and the lower shoulder is gripped by the fuel handling mechanism when the rod is removed 


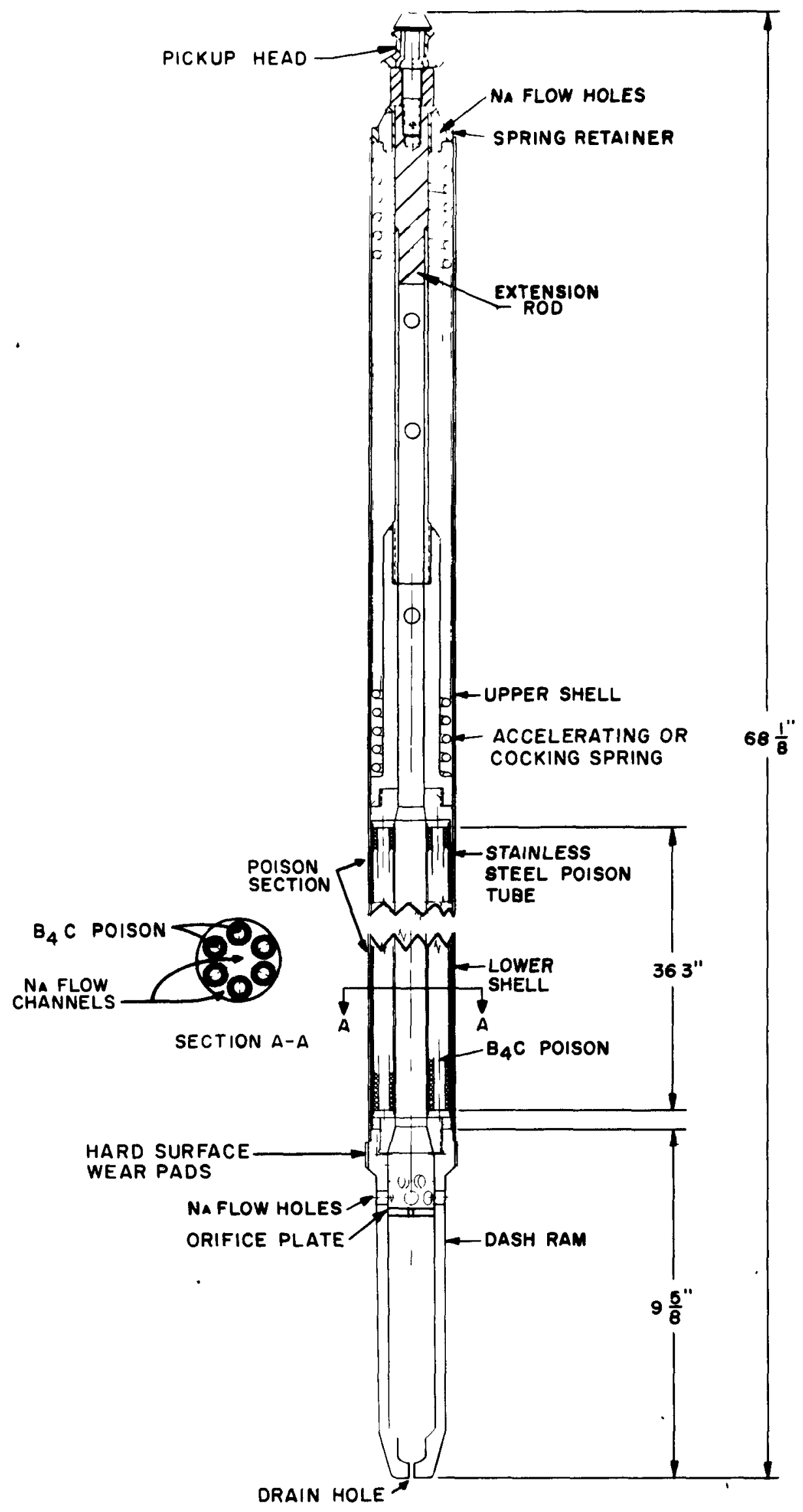

FIG. 4 SAFETY ROD ASSEMBLY 
from the reactor. When fully inserted in the reactor, the handling head of the rod is 2 inches lower than the surrounding core subassemblies, which requires the removal of four adjacent subassemblies before the fuel handling mechanism can remove a safety rod. This provision insures that a rod will not be picked up accidently by the fuel handling mechanism.

\section{DESCRIPTION OF THE SAFETY ROD DRIVE MECHANISM}

The safety rod drive mechanisms are electro-mechanical devices and consist of two major parts: (1) the power unit, Figure 5, and (2) the drive extension, Figure 6. The power unit for each rod is located in the machinery compartment above the rotating shield plug of the reactor. They are mounted on the top plate of the hold-down mechanism and are approximately 24 feet above the tops of the fuel subassemblies in the reactor. The drive extensions extend through the rotating shield plug and the upper sodium plenum, and they are contained inside the safety rod guide tubes.

The safety rods are grasped by the mechanical latch at the lower end of the drive extension (Figure 6, Section D) and are raised or lowered by the power unit through the ball screw and nut (Figure 5). The drive extension penetrates the rotating shield plug by means of a seal thimble which is bolted into the hold-down mounting plate. The reciprocating stroke is sealed by a stainless steel welded bellows which is attached to the seal thimble and the drive extension thus isolating the radioactive primary system gas from the atmosphere outside the reactor. The seal thimble and bellows are located as shown in Section B of Figure 6. The pick-up fingers of the latch are cammed shut by the differential motion between the fingers and cam during the latching operation, and grasp the pick-up head as shown in Section D of Figure 6. The fingers are held in the latched position by the armature of the latch magnet located at the upper end of the extension (Section A of Figure 6).

The latch magnet assembly is also located in the machinery compartment. A cam extension shaft passing upward through the drive extension housing connects the camming parts of the latch to the armature of the latch magnet. With the rod latched and held by the drive extension, a scram is accomplished by inter rupting the current to the latch magnet thus releasing the armature. The combined weight of the armature, cam extension shaft, and cam together with the stored energy of the delatch assist spring, Section A, Figure 6, positively cam the fingers open to release the rod. At the same time, the force of the cocking spring plus the weight of the safety rod tends to pull the safety rod handling head out of the latch.

Release of the safety rods by the latch fingers is indicated to the operator in the control room by the LATCHED lights on the control console going off and the DELATCHED lights switching on. These lights are actuated by the latch-open limit microswitch which is mounted on the latch magnet housing tube just below the armature. The cam extension shaft has ramps 


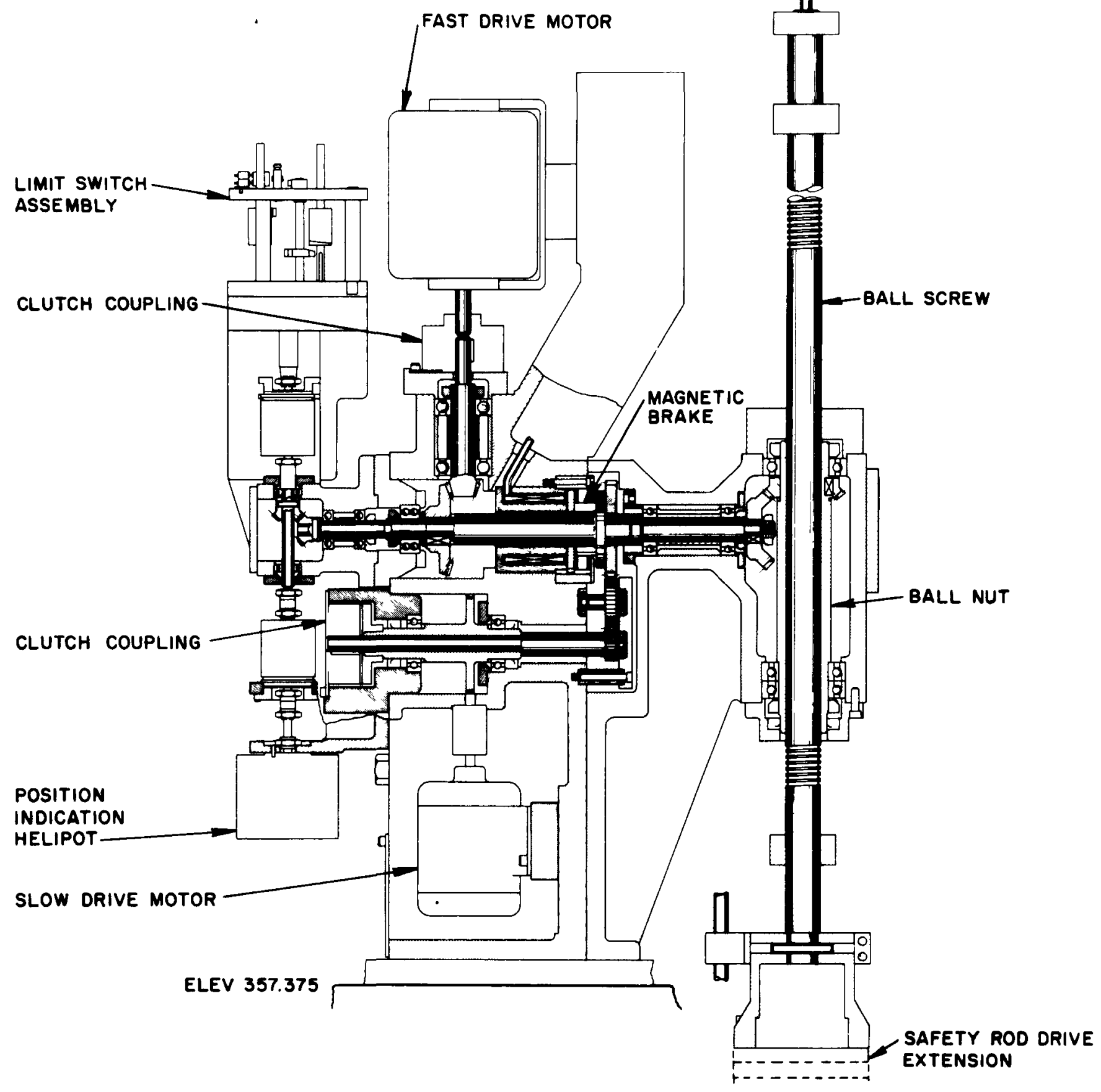

FIG. 5 SAFETY ROD DRIVE ASSEMBLY 


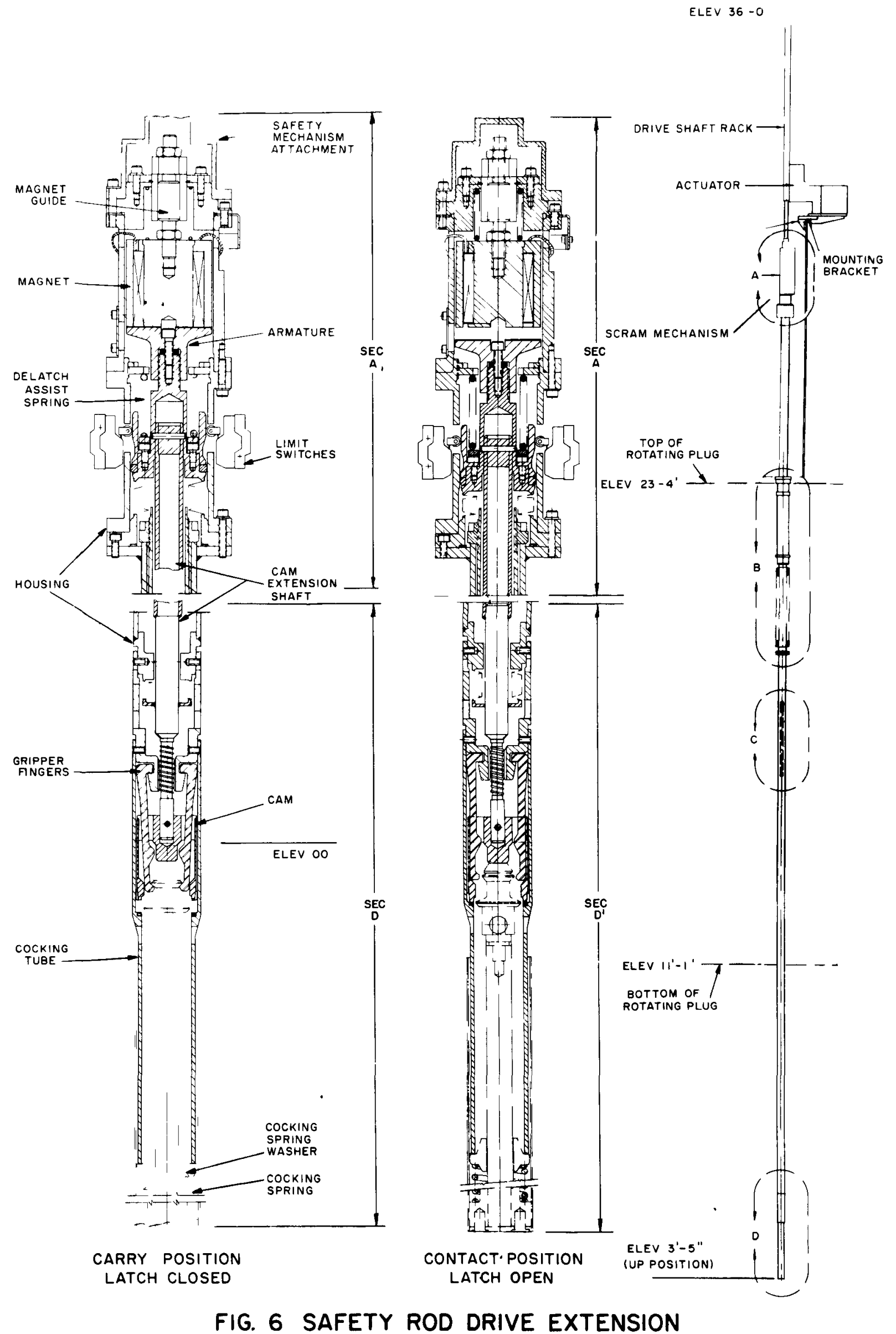


mounted on it and when the rod is released the latch-open microswitch is tripped as a result of the relative motion between the cam extension shaft and the latch magnet housing. 


\section{EXPERIMENTAL PROCEDURE}

\section{A. DESCRIPTION OF THE TEST}

To investigate the effect of sodium flow rate and temperature conditions in the reactor on the safety rod drop time, the test was conducted in two parts.

Part 1 - With the reactor temperature set at $517 \mathrm{~F}$ isothermal and the primary sodium flow rate at the Core A, 200-Mwt value (2.95 $\mathrm{x}$ $10^{6} \mathrm{lbs} / \mathrm{hr} /$ loop), * each of the seven safety rods was first dropped individually into the reactor, and traces of the resulting flux decays were obtained. Traces of the neutron flux decay were also obtained under the same conditions when rods Nos. 1 and 2, Nos. 1 and 4, Nos. 1, 2, and 4, and all seven rods were dropped simultaneously into the reactor. Figure 7 shows the location of these rods in the reactor. To investigate the effect of flow on the drop time, rod No. 1 was dropped again with the sodium flow at the refueling rate $(2.0 \mathrm{x}$ $10^{6} \mathrm{lbs} / \mathrm{hr} /$ loop) and the trace obtained was compared to that obtained at Core A flow rates.

Part 2 - With the reactor at an isothermal temperature of $600 \mathrm{~F}$ and at Core A, 200-Mwt sodium flow rate, each of the seven safety rods was again dropped individually into the reactor, and flux traces were obtained. The results obtained at $600 \mathrm{~F}$ were then compared to those obtained with Core A flow at $517 \mathrm{~F}$ to investigate the effect of temperature on the drop time.

The test procedure used in each part of the test for determining the safety rod insertion times and rod worths is given in detail in Reference 2 . In general, the procedure was as follows:

(a) The isothermal temperature of the reactor and the primary coolant flow was adjusted to the desired values.

(b) The reactor was made critical at a power level which resulted in a current of about $8 \times 10^{-9}$ amperes from the ion chamber that was used for recording flux level data. This value of the ion chamber current was chosen to ensure that a satisfactory signal

\footnotetext{
*The Enrico Fermi reactor has three identical primary coolant loops. Therefore, the total sodium flow rate here was $8.85 \times 10^{6} \mathrm{lb} / \mathrm{hr}$.
} 


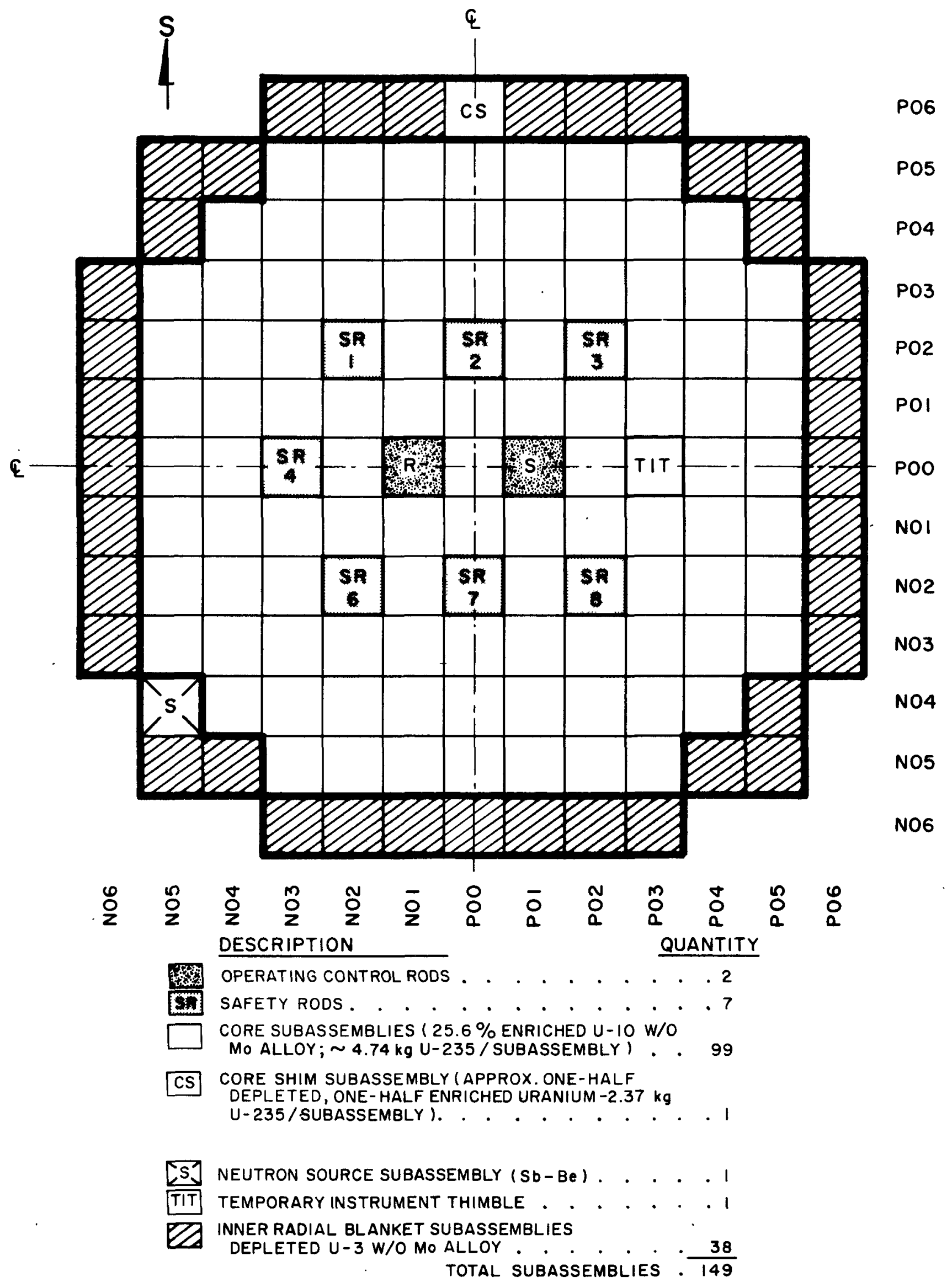

FIG. 7 SAFETY ROD ARRANGEMENT AND CORE LOADING DURING TEST 
to noise ratio existed throughout the time of the rod drop. In practice, the critical power level required to attain this current was approximately $1 \mathrm{kw}$.

(c) After the reactor power level was stabilized at $1 \mathrm{kw}$, the rod or rods of interest were manually released by interrupting the current to the latch magnet. A high-speed recording oscillograph (Sanborn Recorder), installed for recording data during the test, was started manually approximately one second before the rod was released. The oscillograph recorded the flux data from three specially installed neutron detectors during the time of drop; it also recorded the latch-open microswitch and latch magnet voltages prior to and during the drop.

(d) The data on the transient neutron level of the reactor was then analyzed to obtain the rod drop times and rod worths (Section IV).

\section{B. EXPERIMENTAL EQUIPMENT}

To measure the safety rod insertion times and reactivity worths, it was necessary to determine the neutron flux level of the reactor as a function of.time after release of the safety rods. To accomplish this, a high-speed Sanborn recording oscillograph was used to record the signals received from three specially installed neutron detectors after a rod drop. Simultaneously, the oscillograph recorded the voltage across the safety rod latch-open microswitch and the voltage to the latch magnet. From these later data, the exact time of rod release was determined. Sodium flow rate and temperature data were also obtained using the normal plant instrumentation. 1 Figure 8 illustrates the manner in which the above equipment was arranged in the test.

\section{Ion Chamber}

A Reuter-Stokes, Inc. B-10 lined ion chamber, Model RSN-778, with a sensitivity of approximately $3 \times 10^{-13}$ amperes per thermal nv, was located out-of-core in NCT 3 in the graphite shield (Figures 3 and 9). The ion chamber was connected to a Keithley micro-microammeter which was adjacent to the point where the neutron-counter tube penetrated the reactor operating floor. This permitted the cable length, and hence the input capacitance, to be held to a minimum. The output of the micro-microammeter was recorded by the Sanborn recorder.

\section{Fission Counter and $\mathrm{BF}_{3}$ Proportional Counter}

An absolute U-235 fission counter, manufactured by Argonne National Laboratory, was placed at the elevation of the core midplane in an in-core instrument thimble, located in safety rod channel No. 5 (Figure 7). A Twentieth Century BF3 proportional counter, Model 40 FB 70/50/G, was 


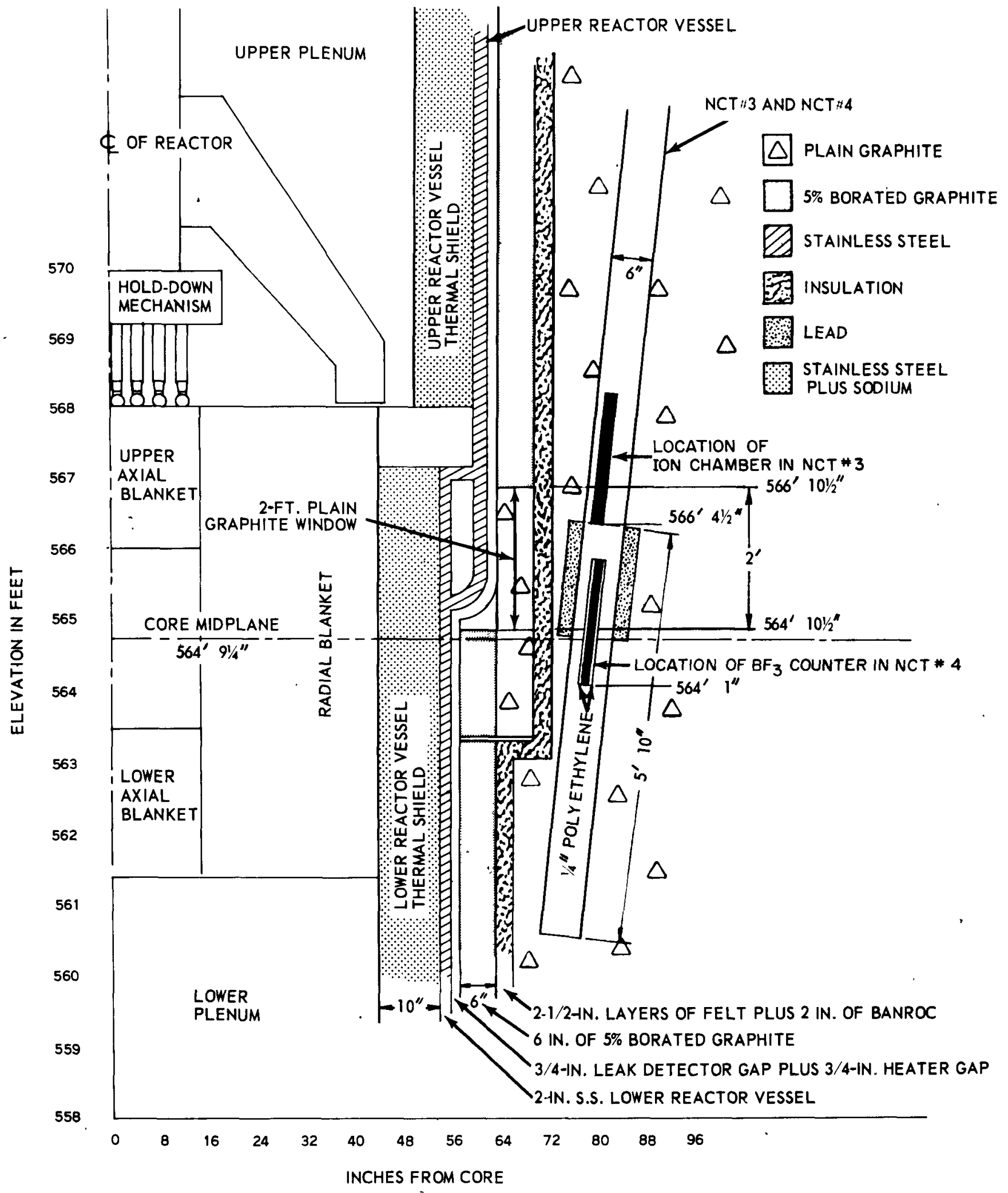

FIG. 9 NEUTRON-COUNTER TUBES NOS. 3 AND 4, SHOWING THE LOCATION OF THE DETECTORS 
located in NCT 4 (Figures 3 and 9). The signals from both of the se counters went to preamplifiers, amplifiers, prescalers and then to the Sanborn recorder. In each case, the prescalers were the first two decades of an RIDL 49-51 scaler. The prescalers reduced the frequency of the pulses to the Sanborn recorder to a rate which could be resolved on the trace. The pulse rate on the Sanborn trace was directly proportional to the neutron flux level in the reactor.

\section{Keithley Micro-Microammeter}

A Keithley micro-microammeter, Model 715, was used to amplify the current from the ion chamber to a level which could be used to drive the Sanborn Recorder.

\section{Sanborn Recorder}

An eight-channel, high-speed Sanborn Recorder, Model 650, was used to record the trace of the ion chamber current, the pulses from the absolute fission counter and the $\mathrm{BF}_{3}$ detector, the voltage across the latch-open microswitch, and the voltage to the latch magnet. All signals were recorded simultaneously on the same strip chart (Figure 10). The recorder also provided timing lines on the chart at a frequency of 100 lines per second. A chart speed of 50 inches per second was used to give the time resolution desired.

\section{REACTOR PLANT CONDITIONS}

The reactor core fuel loading for the test was adjusted to provide sufficient excess reactivity so that criticality could be achieved without withdrawal of the shim control rod. This required an excess reactivity of $600 \mathrm{~F}$ which was greater than the rod worth of 46 cents. This condition was achieved with a loading of 99 full core subassemblies and one core shim subassembly (Figure 7). This reactivity restriction was set because the slow withdrawal rate of the shim rod would have otherwise limited the number of rod drop measurements which could have been made in a day's testing. During the test, the antimony-beryllium neutron source was also in the core in its permanent location at the core-blanket interface (Figure 7). However, the results of the test were not dependent on either the reactivity state of the reactor or the presence of the neutron source, i.e., prior to a rod drop, the reactor power was sufficiently high so that source neutron contributions to the flux during the time of a rod drop were negligible.

The primary system temperature of the reactor was maintained at $517 \mathrm{~F}$ and $600 \mathrm{~F}$ during the two parts of the test. Temperature changes were made using the heat input that resulted from primary sodium pump operation. The reactor temperature was held steady at the desired temperature by balancing the heat input from pump operation with the heat removal by below- 


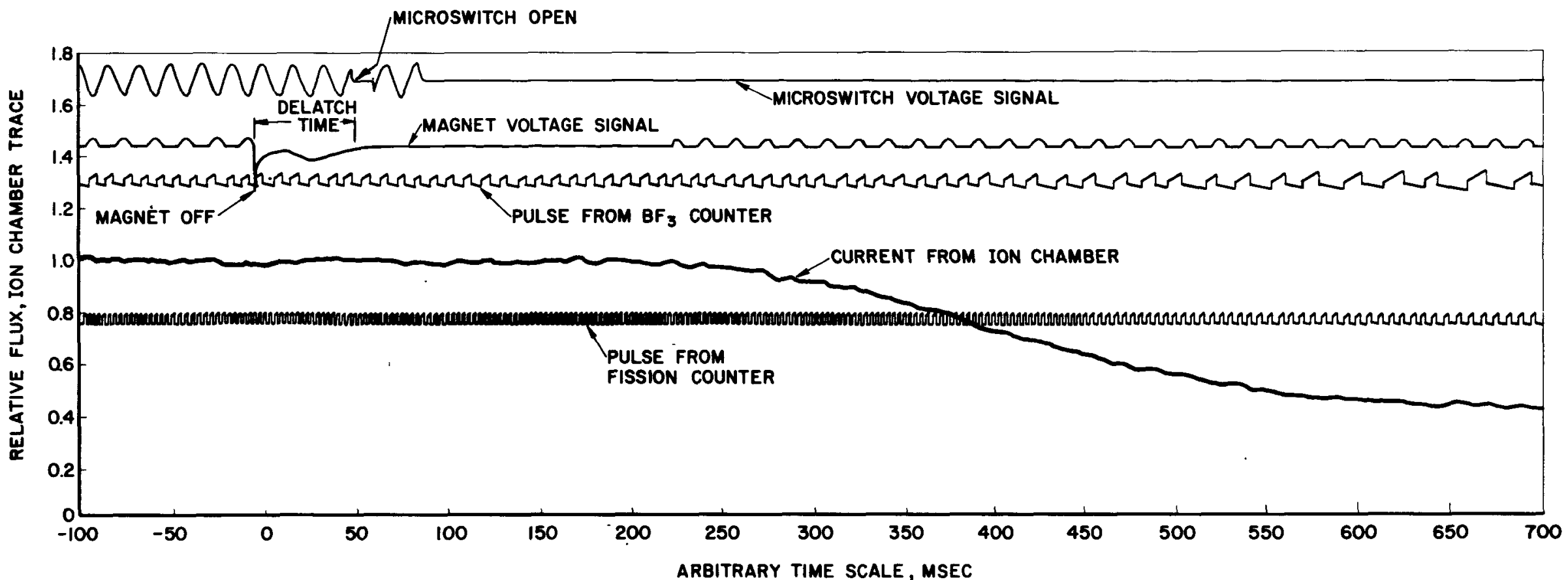

FIG. 10 TYPICAL SANBORN TRACE OF A ROD DROP 
floor ventilation. The auxiliary cooling system, corsisting of the overflow pumps and the primary system cold trap, was operated to reduce the upward drift in temperature when required.

The primary sodium flow rate in the test was varied between refueling flow (2.0 × $10^{6} \mathrm{lb} / \mathrm{hr} /$ loop) and Core A, 200-Mwt design flow (2.95 $\times 10^{6}$ $\mathrm{lb} / \mathrm{hr} /$ loop). To allow the tests to be made at refueling flow, which is 68 per cent of the Core A flow rate, the low sodium flow trip setting of the reactor safety system was reduced from its normal setting of 75 per cent to 40 per cent of the Core $A$ value. The intermediate and power range level scrams were set at flux levels corresponding to powers less than $1 \mathrm{Mw}$.

Another modification was made for the test; the latch magnet mechanisms of the safety rods were revised so that each of the rods could be delatched and scrammed independently into the reactor. 


\section{METHOD OF ANALYSIS}

\section{A. ANALYSIS OF THE ROD DROP DATA}

The particular mechanical design of the safety rods in the Fermi reactor precludes the visual observation of the motion of the rods during a scram. However, an indirect method of deducing reactivity as a function of time after scram, from experimental measurements of the subcritical flux as a function of time, can be used to follow the progress of the rods in a rod drop experiment. 3 Once the time dependent reactivity variation for the rod drop is known, the rod insertion time and rod worth can be found directly.

\section{Time Dependent Reactivity and Flux Relationship}

The basic equations used for the analysis of the data obtained in a rod drop test by this method are the space independent reactor kinetic equations:

$$
\begin{aligned}
& \frac{d \dot{\phi}(t)}{d t}=\left(\frac{1-\beta}{\ell}\right) \cdot k_{e x}(t) \phi(t)-\left(\frac{\beta}{\ell}\right) \phi(t)+\sum_{i=1}^{6} \lambda_{i} C_{i}(t) \\
& \frac{d C_{i}(t)}{d t}=\left(\frac{\beta}{\ell}\right) a_{i}\left[1+k_{e x}(t)\right] \phi(t)-\lambda_{i} C_{i}(t)
\end{aligned}
$$

where:

$$
\begin{aligned}
i & =\text { delayed neutron group }(i=1 \text { to } 6) \\
t & =\text { time after disturbance of steady-state conditions, sec } \\
\beta & =\text { total effective delayed neutron fraction } \\
\ell & =\text { prompt neutron lifetime, sec } \\
k_{e x}(t) & =\text { time dependent excess reactivity, } \Delta \mathrm{k} / \mathrm{k} \\
\phi(t) & =\text { time dependent neutron flux, } \mathrm{n} / \mathrm{cm}^{2} / \mathrm{sec}^{-1} \\
\lambda_{i} & =\text { precursor decay constant, sec } \\
\mathrm{C}_{i}(t) & =\text { time dependent concentration of the precursor of the } \\
\mathrm{a}_{i} & =\text { fraction group of delayed neutrons, nuclei per cm }{ }^{3} \\
& \text { in the } \mathrm{i}^{\text {th }} \text { group }
\end{aligned}
$$


Equations (1) and (2) can be combined to obtain the relationship between the time dependent excess reactivity, $k_{e x}(t)$, and flux, $\phi(t)$, by making use of the initial conditions $(t=0)$ which exist at criticality just before the rod is dropped. These conditions are:

and

$$
\mathrm{k}_{\mathrm{ex}}(0)=0
$$

$$
\frac{d C_{i}(0)}{d t}=0
$$

These conditions correspond to the statements that at time zero, the excess reactivity is zero and the delayed neutron precursor concentrations are in equilibrium. The result obtained by using these initial conditions and combining Equations (1) and (2) is the following integro-differential equa$\operatorname{tion}^{3}$.

$$
\begin{aligned}
\left(\frac{1-\beta}{\beta}\right) k_{e x}(t)= & +\left(\frac{\ell}{\beta}\right) \frac{1}{\phi(t)} \frac{d \phi(t)}{d t}-\frac{\phi(0)}{\phi(t)} \sum_{i=1}^{6} a_{i} e^{-\lambda_{i} t} \\
& -\frac{1}{\phi(t)} \sum_{i=1}^{6} a_{i} \lambda_{i} e^{-\lambda_{i} t} \int_{0}^{t}\left[1+k_{e x}\left(t^{\prime}\right)\right] \phi\left(t^{\prime}\right) e^{\lambda_{i} t^{\prime}} d t^{\prime}
\end{aligned}
$$

where:

$$
\phi(0)=\text { the flux level at time } t=0
$$

To obtain the negative excess reactivity, $k_{e x}(t)$, as a function of time after rod drop from a given set of experimental flux data as a function of time, $\phi(t)$, Equation (3) was put into difference form and programmed in FORTRAN for the IBM-7094. An accurate value for the integral was calculated by use of an iterative procedure that employed interpolation and extrapolation of the available information. A linear interpolation of the flux data was used when necessary.

Figure 11 illustrates the kinetic behavior predicted from Equation (3). In this figure, the calculated time dependent negative excess reactivity is shown for one of the typical time dependent neutron level changes measured in the test.

\section{Data Reduction and Analysis}

After a preliminary analysis of the data, it was concluded that equally reliable data were obtained from the in-core fission counter and the 


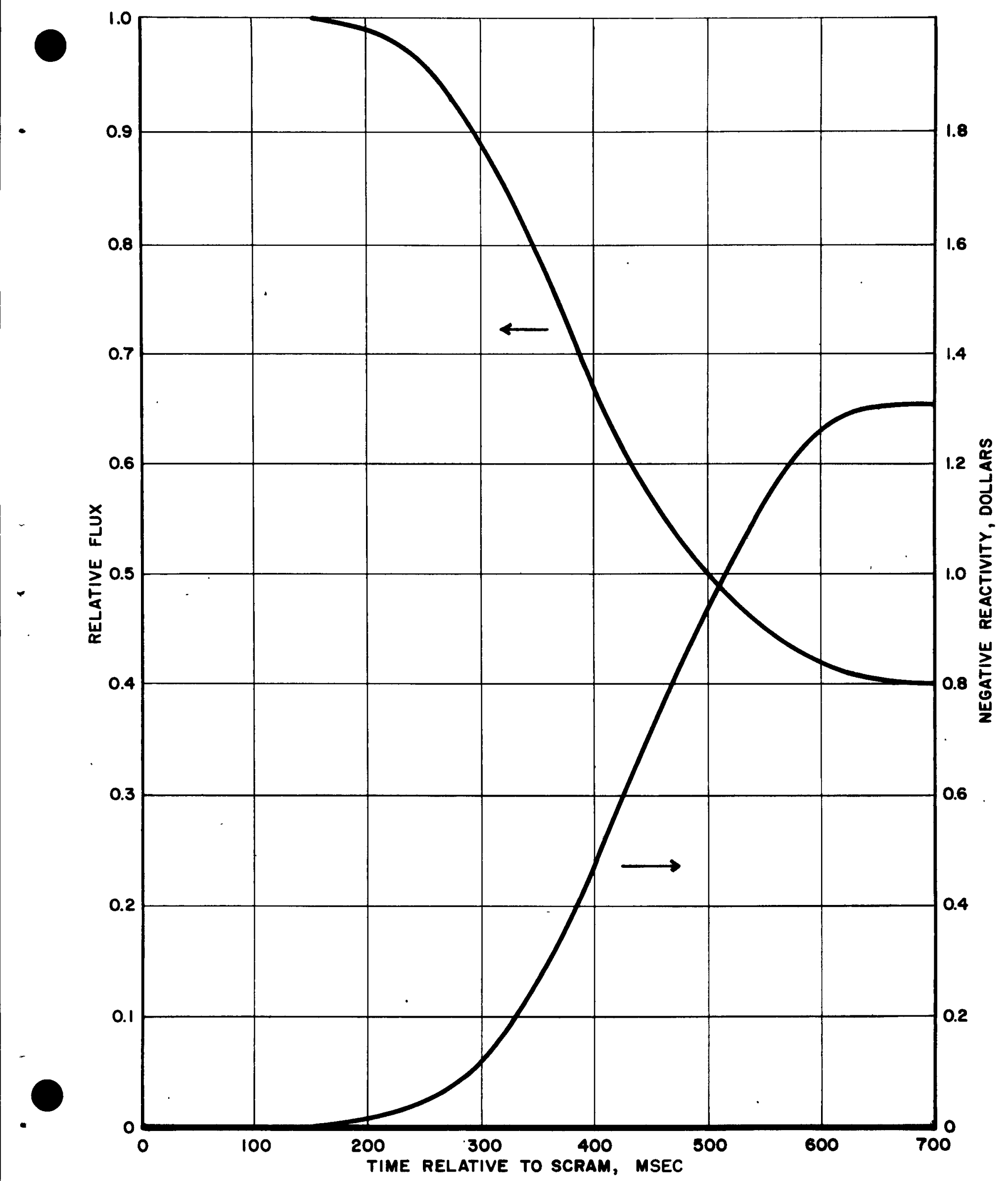

FIG.II TYPICAL FLUX DECAY AND CALCULATED REACTIVITY FOR A ROD DROP EXPERIMENT 
out-of-core $\mathrm{BF}_{3}$ detector and ion chamber.* Therefore, for reasons of resolution and ease, it was decided that only the data from the ion chamber would be analyzed in detail. The ion chamber data were converted to digital form at $50-\mathrm{msec}$ intervals, normalized to unity at steady-state power (critical power), plotted to determine any gross reading errors and put in a form suitable for the computer program.

The output of the computer program was a table of the negative reactivity, values at the end of each $50-\mathrm{msec}$ time interval for which the flux was specified to the computer. The reactivity was converted from units of $\Delta \mathrm{k} / \mathrm{k}$ to dollars using the relationship l dollar $=0.00662 \Delta \mathrm{k} / \mathrm{k}$. The tabular data was then plotted to show the reactivity as a function of time after scram; from this curve, it was possible to determine the worth of the safety rod and the rod drop time.

\section{Basic Data}

The delayed neutron data that were used in the computer analysis are given in Table I. The values used are nominal, and are based on the best available data. 1 The uncertainties in these values caused uncertainties of about \pm 1 per cent in the reactivities obtained from the computer analysis. In. the analysis, a prompt neutron lifetime value of $\ell=1.37 \times 10^{-7} \mathrm{sec}$ and a total effective delayed neutron fraction value of $\beta=0.00662$ were used. These two quantities appear only as a quotient in Equation (3), and it was found that the results of the analysis are very weakly dependent upon the value of this ratio. Therefore, the values used for lifetime and delay fraction had little effect on the results obtained for this test.

TABLE I - DELAYED NEUTRON DATA

\begin{tabular}{c} 
Group, i \\
\hline 1 \\
2 \\
3 \\
4 \\
5 \\
6
\end{tabular}

\begin{tabular}{c}
$a_{i}$ \\
\hline 0.0371 \\
0.1918 \\
0.1858 \\
0.3958 \\
0.1571 \\
0.0393
\end{tabular}

$\lambda_{i}, \sec ^{-1}$
0.01275
0.03196
0.1204
0.3226
1.405
3.944

*The current from the ion chamber was directly proportional to the neutron flux level in the reactor. In the case of the fission counter and $\mathrm{BF}_{3}$ detector pulses, the flux was proportional to the pulses per unit time; therefore, to obtain the time dependent flux from the pulse data, the pulse rates per unit time were read directly from the chart and plotted versus time. 


\section{B. DETERMINATION OF ROD WORTH}

The rod worth was equal to the total measured change in excess reactivity, $k_{e x}(t)$, as a rod was dropped. Unshadowed, partially shadowed and fully shadowed worths of individual rods could be obtained from the test measurements as well as the ganged worth of all seven rods. The unshadowed worths were obtained for each safety rod directly from the single rod drop reactivity data. Partially and fully shadowed rod worths were obtained from the reactivity changes measured during the two and three simultaneous rod drops by subtracting the unshadowed worths of the rod(s) considered to be the cause of the shadowing from the respective measured multiple rod worths. For example, the partially shadowed worth of rod No. 1 was found by subtracting the unshadowed worth obtained for rod No. 2 from the multiple worth obtained for rods Nos. I plus 2. Similarly, the fully shadowed worth of rod No. 1 was found by subtracting the unshadowed worths obtained for rods Nos. 2 plus 4 from the multiple worth obtained for rods Nos. 1 plus 2 plus 4. From these data, the per cent shadowing could be determined by taking the ratio of the shadowed to the unshadowed rod worths. The ganged worth of all seven rods was obtained directly from the simultaneous seven rod drop data.

\section{DETERMINATION OF ROD DROP TIME}

The determination of the rod drop time from the data was more involved than the determination of rod worth. For the purpose of the analysis, the total rod drop time was considered as three separate time intervals.

Delatch Time - The time interval between the interruption of the current to the latch magnet and the activation of the latch-open microswitch.

Lag Time - The time interval between the activation of the latchopen microswitch and the insertion of 5 per cent of the total negative reactivity.

Insertion Time - The time interval between the insertion of 5 per cent and 95 per cent of the total negative reactivity.

One-hundred per cent reactivity insertion was not used here because it was difficult to determine accurately the last few per cent of reactivity insertion from the flux traces. For conformity, the 95 per cent value was chosen as the basis for the definition of insertion time. The difference between the actual insertion time and the insertion time measured in the test using this approximation is very small.

The delatch time was determined directly from the data obtained for each test on the Sanborn strip chart (Figure 10). The lag time was found by combining the information on the strip chart with the results of the computer 
analysis, i. e., by measuring the time lapse between activation of the latchopen microswitch and 5 per cent reactivity insertion. The insertion time was determined from the plot of the computer analysis by measuring the time interval between 5 and 95 per cent reactivity insertion. The total drop time was the sum of the three time intervals. 


\section{EXPERIMENTAL RESULTS}

\section{A. ROD DROP TIMES}

Figure 10 is a trace of the Sanborn strip chart data obtained for one of the rods dropped during the test. Similar traces were obtained for all safety rods tested. In each case, the safety rod delatch time was determined directly from the trace. The safety rod lag and insertion times were found by reading the flux decay as a function of time from the trace and using the values in Equation (3) to solve for the reactivity variation as a function of time (Section IV). Figure 11 shows the time dependent reactivity change that was calculated for one of the measured time dependent flux changes. This is typical of the curves obtained for all rods tested. Table II gives the resulting experimentally determined safety rod delatch, lag and insertion times for all the tests made at $517 \mathrm{~F}$ and $600 \mathrm{~F}$. The sum of the three time intervals is the safety rod drop time. The values for the time intervals given in Table II are estimated to be correct to within $\pm 25 \mathrm{msec}$. The data shows that within the experimental accuracy, there was no observed effect on the drop times due to temperature and flow rate changes in the reactor. Table III lists the mean time intervals obtained by averaging the results of the single rod drop test data in Table II. For the purpose of comparison, the predicted time intervals, based on rod drop tests conducted in water, 4 are given in Table III. The data indicate, that with the exception of the delatch time, the predicted drop time intervals agree well with the mean of the measured values. The measured delatch time is considerably less than predicted; however, this was expected because the predicted delatch time determined by the water tests, included the electronic response time of the safety system. The measured delatch time in the reactor was determined with manual scram and consequently the electronic time delay of the safety system was not included in the measurements. The measured delatch time was only the time required for the safety rods to move the $3 / 4$ of an inch necessary to trip the delatch microswitch.

\section{B. ROD WORTHS}

The amount of reactivity change measured in each test drop, i.e., the rod worth, is given in Table IV. It was found directly from the reactivity a's a function of time curve, which was plotted using the data from the computer analysis (Section IV). There is an estimated uncertainty in the results of about 3 per cent. The predicted rod worths are also included in Table IV. The predictions are based on a loading of 535 grams of B-10 per rod and critical experiment data of boron worth. ${ }^{5}$ Actually, four of the rods were built with a loading of 507 grams of B-10 and the other four with a loading of 
TABLE II - EXPERIMENTAL VALUES OF THE SAFETY ROD DROP TIME INTERVALS

\begin{tabular}{|c|c|c|c|c|c|c|c|c|}
\hline \multirow[t]{2}{*}{ Rod No. } & \multicolumn{2}{|c|}{$\begin{array}{c}\text { Delatch Time, } \\
\text { msec } \\
\end{array}$} & \multicolumn{2}{|c|}{$\begin{array}{c}\text { Lag Time, } \\
\text { msec }\end{array}$} & \multicolumn{2}{|c|}{$\begin{array}{c}\text { Insertion Time, } \\
\text { msec }\end{array}$} & \multicolumn{2}{|c|}{$\begin{array}{c}\text { Drop Time, } \\
\text { msec }\end{array}$} \\
\hline & $517 \mathrm{~F}$ & $600 \mathrm{~F}$ & $517 \mathrm{~F}$ & $600 \mathrm{~F}$ & $517 \mathrm{~F}$ & $600 \mathrm{~F}$ & $517 \mathrm{~F}$ & $600 \mathrm{~F}$ \\
\hline $1^{a}$ & 33 & 36 & 230 & 218 & 335 & 350 & 598 & 604 \\
\hline 2 & $\ldots b$ & 47 & 235 & 231 & 350 & 380 & - - b & 658 \\
\hline 3 & 50 & 56 & 230 & 238 & 345 & 325 & 625 & 619 \\
\hline 4 & $\ldots c$ & 43 & $--c$ & 226 & 340 & 320 & 613 & 589 \\
\hline 6 & 40 & 49 & 241 & 217 & 325 & 350 & 606 & 616 \\
\hline 7 & 40 & 45 & 243 & 227 & 345 & 345 & 628 & 617 \\
\hline 8 & 39 & 39 & 244 & 242 & 355 & 355 & 638 & 636 \\
\hline $1 \& 4$ & 36 & & 231 & & 370 & & 637 & \\
\hline $1 \& 2$ & 39 & & 238 & & 330 & & 607 & \\
\hline $1,2 \& 4$ & 34 & & 240 & & 360 & & 634 & \\
\hline All 7 & 44 & & 238 & & 335 & & 617 & \\
\hline $\mathrm{l}^{\mathrm{d}}$ & 38 & & 220 & & 330 & & 588 & \\
\hline
\end{tabular}

a. The sodium flow rate was the Core A, $200 \mathrm{Mwt}$ value $(2.95$ $x 10^{6} \mathrm{lb} / \mathrm{hr} /$ loop) for all measurements with the exception of 1 d.

b. This interval could not be determined because the latch magnet current was not recorded during the rod drop.

c. This interval could not be determined because the delatch microswitch current was not recorded during the rod drop.

d. The sodium flow rate was at refueling value $\left(2.0 \times 10^{6}\right.$ $\mathrm{lb} / \mathrm{hr} /$ loop/.

TABLE III - PREDICTED VALUES OF THE

SAFETY ROD DROP TIME INTERVALS

\section{Interval}

Delatch Time

Lag Time

Insertion Time

Drop Time
Predicted Value, msec

100

230

390

720
Median Value Measured, All Rods, msec

618 


\section{TABLE IV - EXPERIMENTAL AND PREDICTED SAFETY ROD WORTHS}

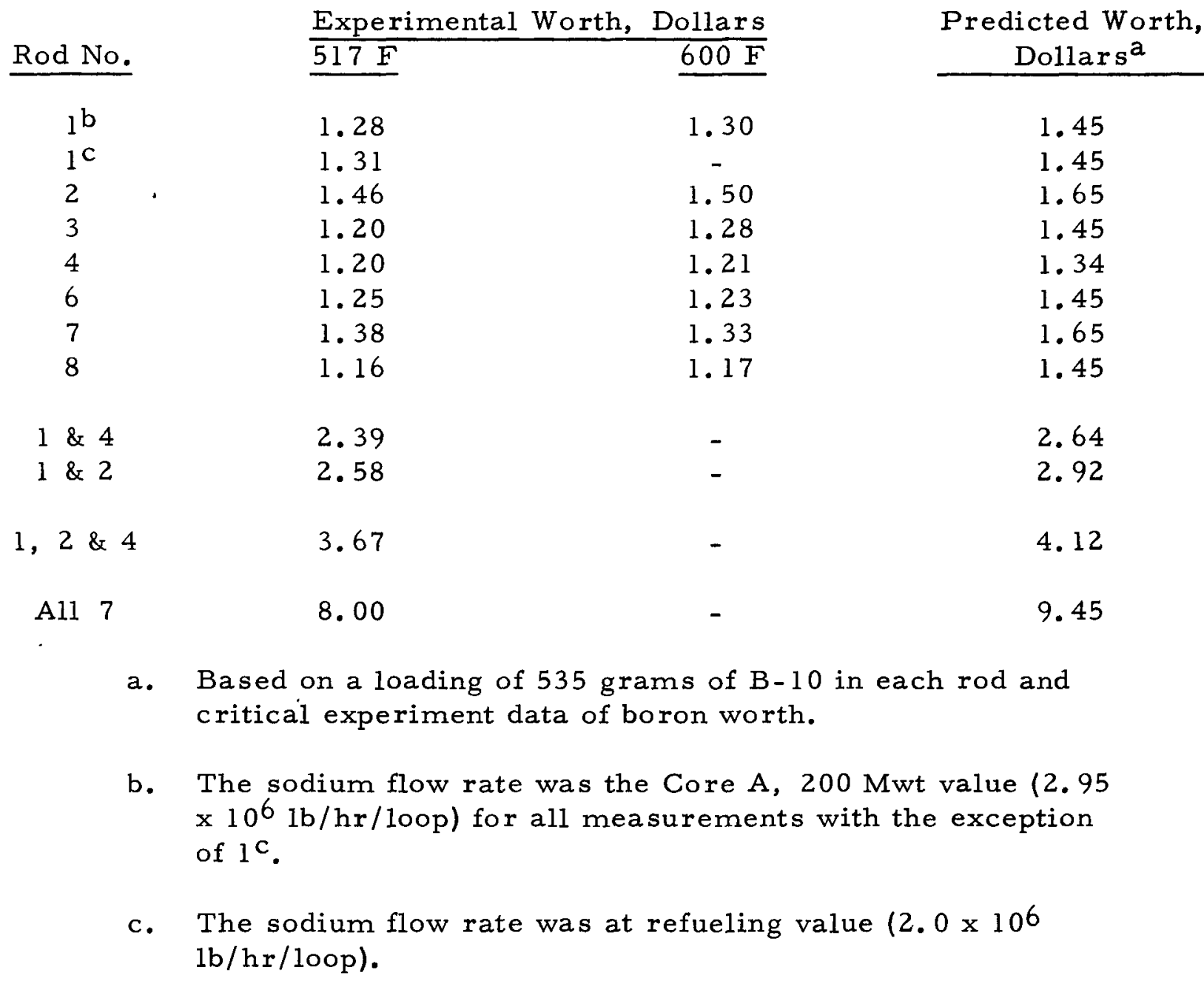

546 grams of B-10. The B-10 loadings of the rods in each position, along with their appropriate serial numbers are given in Table $\mathrm{V}$.

From Table IV, it is seen that the measured unshadowed rod worths obtained from the single rod drops are less than predicted in all cases. The average discrepancy is, about 15 per cent. Although some of the differences between predicted and measured unshadowed rod worth can be attributed to the differences in B-10 loading, the discrepancy still exists for those rods in which the actual B-10 loading is larger than the loading on which the prediction was based. This difference can be attributed to changes which have been made in the core design since the time of the critical experiment, and an underestimate of the rod self-shielding in the critical experiment. 


\section{TABLE V - BORON LOADING OF THE SAFETY RODS}

$\underline{\text { Position }}$

1

2

3

4

6

7

8

$5 *$
Se rial Number

$430192-90$

$430192-87$

$430192-89$

$430192-84$

$430192-83$

$430192-85$

$430192-88$

430192-86
B-10 Loading, $g$

507

507

507

546

546

546

507

546

*Not in reactor

The shadowing effects of adjacent safety rods on rod No. 1 were calculated (Section IV, B) from the multiple drop worths given in Table IV. The partial and full shadowing effects are 12 and 21 per cent, respectively. They agree, within the limits of experimental error, with the predicted values of 11 and 22 per cent, respectively. 5

The measured worth of the seven ganged rods is given in Table IV. As indicated, the experimental ganged worth is also 15 per cent less than predicted. This result is consistent with the fact that the individual unshadowed rod worths are 15 per cent less than predicted and the per cent shadowing is in close agreement with predictions. 


\section{CONCLUSIONS}

The measurements of safety rod drop time made in the Enrico Fermi reactor show that (1) the rod drop characteristics differ little among the rods tested, (2) the drop times agree well with predictions and (3) the drop times show no strong sodium flow rate or temperature dependence. The spread in measured drop times at constant flow rate and temperature is sufficiently small to justify the first conclusion. The second conclusion is supported by the comparison between measured and predicted times. The differences in the data when either flow rate or temperature were changed are sufficiently small, and are equally well distributed between increases and decreases in the drop time intervals, to justify the third conclusion. The median values, averaged over all the tests, for the measured drop time intervals are actually slightly less than the predicted values. This last result can probably be attributed to the fact that the predicted data were obtained from drop tests conducted in water, ${ }^{4}$ which has a viscosity that differs slightly from that of sodium. In addition, the prediction of the delatch time was based on automatic scram, whereas the experiments in the reactor were performed with manual scram; therefore, the electronic time delay of the safety system was not included in the reactor measurements.

The safety rod worths obtained from analysis of the rod drop test data show quite a large variation among individual rods. However, the differences among the rods appear to be reasonable in view of the different core locations of the rods and the known differences in their B-10 loading. Although the measured shadowing (per cent shadowing) of the safety rods on one another is in agreement with predictions, the measured absolute rod worths are about 15 per cent less than predicted. This is true for the unshadowed, shadowed, and ganged rod worths. This could be explained by a misinterpretation of the earlier calibration data from the critical experiment or by changes which have been made in the core design since the time of the critical experiment. Further understanding of the discrepancy between measured and predicted rod worths will be gained from future tests when more detailed calibration measurements are made. 


\section{REFERENCES}

1. PRDC, "Enrico Fermi Hazards Summary Report and Technical Information", Volumes 1 - 7, Revised March 1964.

2. R. E. Horne, "Safety Rod Drop Test", Enrico Fermi Nuclear Test Procedure No. 8, 1962.

3. H. L. McMurry, "Measurement of $k_{\text {eff }}$ by the Rod Drop Method", IDO$16241,1955$.

4. APDA Test Memo No. 13, "Safety Rod Drop Test", September 28, 1959.

5. C. E. Branyan, "Core A Critical Studies for the Enrico Fermi Atomic Power Plant on ZPR-III", ANL-6629, 1962. 


\section{ACKNOW LEDGEMENT}

This work represents the combined efforts of many individuals. In addition to the regular staff members listed in the foreword, the authors would like to recognize the contribution made to the conduct and analysis of this test by I. J. Puig of Commissariat A L'Energie Atomique, Cadarache, France. 